\title{
Perception is Reality, and Reality Drives Perception: No Time to Celebrate Yet
}

\author{
Joseph R. Betancourt, MD, MPH \\ Massachusetts General Hospital, Harvard Medical School, Boston, MA, USA.
}

J Gen Intern Med 33(3):241-2

DOI: $10.1007 / \mathrm{s} 11606-017-4263-\mathrm{Z}$

(c) Society of General Internal Medicine 2017

$P$

This is often said, but rarely understood, and for caregivers, it is what we face every day when we see patients. Patients' perception of us, and of our health care system and the team around us, informs, and is, their reality. Their perception is built on a multitude of factors, including their own health care experiences and those of family and friends. For some, this perception is also shaped by other things, including our nation's history, the history of medicine, and the current political context. All of this often sits silently in the exam room with us as we care for patients, and impacts how they interact with us, how comfortable they feel, how activated they are, and how willing they may be to engage in participatory, shared decision-making.

In this issue of the Journal of General Internal Medicine, Nguyen et al. ${ }^{1}$ look at a key factor that impacts patients' perceptions as well as their reality - perceived discrimination. By conducting an analysis of the Health and Retirement Study from 2008 to 2014, and focusing on the responses of black, white, and Hispanic participants, the research team aimed to monitor trends in patient-reported discrimination, defined by the frequency of receiving poorer service or treatment-compared to others - from doctors or hospitals. The authors found that the estimated prevalence of experiencing discrimination in health care among blacks with a major chronic condition was $27 \%$ in 2008 , declining to $20 \%$ in 2014 . Reports of receiving poorer service or treatment were stable for whites during this time, and the black-white difference in reporting any health care discrimination declined from $8.2 \%$ in 2008 to $2.5 \%$ in 2014. There was no clear trend for Hispanics; blacks reported race, and whites age, as the most common reason for discrimination. This is certainly good news, but before we jump to any major conclusions or premature celebrations in light of this progress, let us review what we know about perceived discrimination and its effector arm, patient mistrust.

Trust is a crucial element in the therapeutic alliance between patient and health care provider. It facilitates open communication and is directly correlated with adherence to physician

Published online January 3, 2018 recommendations and patient satisfaction. ${ }^{2}$ Patients who perceive discrimination and do not trust their health care providers are less satisfied with the care they receive. ${ }^{3}$ Based on historical factors of racism, discrimination, and segregation in the United States, along with medical experimentation and exploitation (perhaps most poignantly represented by the Tuskegee Syphilis Study and the treatment of Henrietta Lacks), African-Americans may be particularly mistrustful of health care providers. ${ }^{4-6}$ Surveys have shown that, compared to their white counterparts, African-Americans are more likely to feel that they have been treated unfairly in the health care system in the past, and more afraid of being treated unfairly in the future based on their race/ethnicity. ${ }^{7}$ It is no surprise that they would anticipate, and perceive, discrimination at higher rates than their white and Hispanic counterparts; their reality has them on guard, concerned, worried, and mistrustful when they interact with us - despite our best intentions. We should not assume that every African-American is mistrustful and perceives discrimination at every turn, but we would be naive to think these issues are not prevalent. Lack of awareness and tools to build trust limit our ability to deliver high-quality care to diverse populations.

There are two important points worth making about the Nguyen et al. study. ${ }^{1}$ To begin, the survey period of 2008 to 2014 unfortunately represents a different context than the one we are living in today. Divisive, even racist rhetoric from the highest echelons of our political sphere has unearthed a new reality, one which many hoped we had moved beyond. The "post-racial" era supposedly marked by the election of this country's first African-American president has swung with the force of a 10-ton pendulum. People, and patients, feel emboldened to say and do things that in years past would have been unheard of and considered racist. I believe that if we were to monitor perceived discrimination today, we would see a new spike among blacks that would blunt the improvements this research identified. In fact, almost paradoxically, but not unexpectedly given the tone and tenor of our national discourse, a recent survey by National Public Radio, the Robert Wood Johnson Foundation, and Harvard T.H. Chan School of Public Health found that $55 \%$ of whites surveyed believed that there was discrimination against whites in the United States, yet interestingly, only $5 \%$ reported actually experiencing discrimination in health care. ${ }^{8}$ In contrast, $92 \%$ of African Americans believed that discrimination against African Americans exists in America today, while 32\% reported actually experiencing discrimination in health care. 
In addition, the recent enthusiasm and energy around addressing the social determinants of health-poverty, lack of educational opportunities, limited safe spaces for exercise, and few options for obtaining healthy foods or environments free of airborne pollutants, to name a few - has led many to review our history for the purposes of better understanding how these conditions emerged and engulfed vulnerable and minority populations. The lessons here are eye-opening, particularly as they relate to African-Americans in the United States. In cities across the country, the embodiment of institutional racism in policies and tactics has torn apart the fabric of communities that were recovering from the legacy of slavery and Jim Crow laws. The list is startling: transportation policies that decimated parks and gathering places and tore communities of color in half; environmental policies that located incinerators and diesel bus routes in specific vulnerable communities; public education policies that chronically underfunded certain communities compared to others; public housing policies that allowed only women and children as residents, instead of fathers and intact families; criminal justice sentencing policies that delivered harsher punishment for drugs, such as crack, seen predominately in communities of color and more lenient sentences for forms of the same drug (powder cocaine) seen predominately in communities of higher socioeconomic status. ${ }^{9,10}$ A good example is the shift in management of the heroin (and opioid) epidemic. In the 1970s and '80s, when these drugs were the scourge of minority communities, a punitive, criminal justice-based approach was used for those who were addicted, resulting in mass incarceration. Today, with the epidemic spreading primarily to majority communities, a treatment and rehabilitative approach is favored. Same drugs, same epidemic, handled completely differently in different communities. In Chicago (and undoubtedly other cities) today, depending on where you are caught, you are treated differently. We do not have to compare past to present. The negative impacts of the social determinants, and where they take their toll, are not coincidental. It is no wonder that this would translate to distrust in health care. Reality drives perception.

So, as caregivers, where do we go from here? We should not feel that all is lost. There are practical, actionable, and achievable strategies to bridge the gap of patient mistrust and perceived discrimination. First, it is critical and incumbent upon us to understand our nation's history and the history of the communities we care for, including the history of different populations, which is usually not taught during our formal education in its full color or complexity. Nowadays, accessing this information is easier than ever. Second, with this history will come the need for empathy. The more we work to understand the experience of others, the better we will be able to find common ground, and avoid demonizing patient behaviors that might seem difficult, inappropriate, or unbecoming. Unlike understanding history, this is much more challenging, given the polarizing tribalism that we are in the midst of today; across the country, empathy appears to be scarce. Third, we need to address the potential for mistrust and perceived discrimination directly with our patients. A simple question such as "have you ever had a bad experience in health care I should know about,", with some time for response, can almost immediately shed light on a patient's perspective related to trust and treatment in health care. A question like this can be a powerful tool, as patients of all stripes may have had a bad experience that has made them mistrustful and that informs their response to us, our colleagues, and our health system, and undoubtedly their health beliefs and behaviors. Finally, once we open that door, we must demonstrate that we are different, and provide strong reassurance to that effect. We have cared to ask. We understand. We want a fresh chance. We commit to open communication when patients feel mistrustful or concerns emerge. Evidence demonstrates that people can be mistrustful of organizations and institutions, but as individuals, we can break through and build trust.

In the end, I am hopeful. I do believe we can turn the corner again and build on the improvements the authors have discovered here. That being said, it may get worse before it gets better. It will require courage and conviction on the part of caregivers and health care institutions to ensure that no patient perceives discrimination in health, and instead expects equitable, highquality care. We must change reality to alter perceptions.

Corresponding Author: Joseph R. Betancourt, MD, MPH; Massachusetts General Hospital, Harvard Medical School, Boston, MA, USA (e-mail: JBETANCOURT@mgh.harvard.edu).

\section{Compliance with Ethical Standards:}

Conflict of Interest: The author declares that he does not have a conflict of interest.

\section{REFERENCES}

1. Nguyen TT, Vable AM, Glymour MM, Nuru-Jeter A. Trends for reported discrimination in health care in a national sample of older adults with chronic conditions. J Gen Intern Med. 2017. https://doi.org/10.1007/ s11606-017-4209-5.

2. Peterson LA. Racial differences in trust: reaping what we have sown. Med Care. 2002;40(2):81-4.

3. Thom DH, Campbell B, for the Stanford Trust Study Physicians. Patientphysicians trust: an exploratory study. J Fam Pract. 1997;44:169-76.

4. Gamble V. Under the shadow of Tuskegee: African-Americans and health care. Am J Public Health. 1997;87(11):1773-8.

5. Corbie-Smith G. The continuing legacy of Tuskegee Syphilis Study: considerations for clinical investigation. Am J Med Sci. 1999;317:5-8.

6. Brandt AM. Racism and research: the case of the Tuskegee syphilis study. Hastings Cent Rep. 1978;8:21-9.

7. Race, Ethnicity and Medical Care, A Survey of Public Perceptions and Experiences (KFF) Kaiser Family Foundation. www.kff.org. Accessed 11 March 2005

8. Discrimination in America. National Public Radio, Harvard Chan School of Public Health and The Robert Wood Johnson Foundation, 2017. https://www.rwjf.org/en/library/research/2017/10/discrimination-inamerica-experiences-and-views.html. Accessed 10 Nov 2017.

9. Byrd WM, Clayton LA. An American Health Dilemma, Volumes 1 and 2. New York: Routledge; 2000.

10. The war on drugs is an epic fail. https://genius.com/Jay-z-the-war-ondrugs-is-an-epic-fail-annotated. Accessed 10 Nov 2017. 